\title{
Oportunidades de emprego e trabalho para egressos do sistema prisional: revisão sistemática
}

\author{
Employment and work opportunities \\ for egressed from the prison system: a \\ systematic review
}

\section{Juliana Ferreira da Silva' (1) \\ Luiza Gayão Araújo e Silva² (1) Maria Liz Cunha de Oliveira 3 (1) Maria Aparecida Penso 4 (1)}

\begin{abstract}
1-2Universidade Católica de Brasília (Brasília). Distrito Federal, Brasil. juliana.dasilva.ucb@gmail.com, luizagayao@gmail.com ${ }^{3}$ Autora para correspondência. Universidade Católica de Brasília (Brasília). Distrito Federal, Brasil. lizcunhad@gmail.com ${ }^{4}$ Universidade Católica de Brasília (Brasília). Distrito Federal, Brasil. mariaaparecidapenso@gmail.com
\end{abstract}

\begin{abstract}
RESUMO | OBJETIVO: Analisar a literatura científica sobre a reinserção social de egressos do sistema prisional no mercado de trabalho. MÉTODO: Foi realizada uma revisão sistemática com busca e seleção de estudos via Portal de Periódicos da Coordenação de Aperfeiçoamento de Pessoal de Nível Superior (Capes) de 2009 a 2019, adotando critérios de disponibilidade na íntegra, em língua espanhola, inglesa ou portuguesa. A busca, seleção, avaliação de qualidade e extração de dados foram realizadas independentemente por duas pesquisadoras. Foram encontradas 555 produções, sendo filtradas a partir de título e resumo e, na sequência, inventariados tecnicamente; posteriormente, foi realizada a análise do texto na íntegra dos artigos selecionados nas etapas anteriores. RESULTADOS: Foram avaliados 10 artigos, onde seis estudam a inserção do egresso no mercado de trabalho na perspectiva do sexo masculino e apenas um artigo trata dos dois sexos. Quanto à perspectiva de gênero, não foi encontrada referência. Os resultados dos estudos analisados tiveram objetivos distintos, tendo em comum a investigação de diferentes tipos de inserção de ex-detentos no mercado de trabalho e as tendências dessas produções são caracterizadas pela restrição de encontrar trabalho. CONCLUSÃO: A análise dos artigos verificou que os egressos do sistema prisional enfrentam uma confluência de fatores de difícil superação para alcançar algum tipo de trabalho, quais sejam, o estigma que pesa sobre eles, o baixo nível de escolaridade e a precarização do trabalho.
\end{abstract}

PALAVRAS-CHAVE: Revisão Sistemática. Prisão. Solicitação de Emprego. Inclusão social.

\begin{abstract}
OBJECTIVE: To analyze the scientific and scientific literature on the social reintegration of former prisoners into the labor market. METHOD: A systematic review was carried out with search and selection of studies via the Portal of Periodicals of the Coordination for the Improvement of Higher Education Personnel (Capes) from 2009 to 2019, adopting availability criteria in full, language (Spanish, English, or Portuguese). The search, selection, quality assessment, and data extraction were carried out independently by two researchers. A total of 555 productions were found, being filtered based on title and summary and, subsequently, technically inventoried later, the full-text analysis of the articles selected in the previous steps was carried out. RESULTS: 10 articles were evaluated, of which six studied the insertion of the graduate in the labor market from the male perspective; only one article deals with both sexes. Regarding the gender perspective, we found no reference. The results of the analyzed studies had different objectives, having in common the investigation of different types of insertion of ex-prisoners in the labor market, the restriction of finding work characterizes the tendencies of these productions. CONCLUSION: The analysis of the articles found that the graduates of the prison system face a confluence of factors that are difficult to overcome in order to achieve some type of work, namely, the stigma that weighs on them, the low level of education, and the precariousness of work.
\end{abstract}

KEYWORDS: Prison. Review. Job application. Social inclusion. 


\section{Introdução}

O presente trabalho apresenta uma etapa da revisão bibliográfica do projeto de pesquisa intitulado “Egressos do Sistema Prisional: Histórias que importam", que tem como objetivo avaliar as histórias de vidas de egressos do sistema prisional no Distrito Federal, Brasil.

A equipe de pesquisa estabeleceu um protocolo de extração dos dados da literatura organizado em cinco conjuntos: trajetórias antes da prisão, trajetórias durante a prisão, trajetórias depois da prisão, metodologia da história de vida e perfil das pessoas aprisionadas. O conjunto dos dados sobre as trajetórias depois da prisão contempla as oportunidades de emprego e o trabalho ao egresso, apresentados neste artigo.

Quanto ao perfil das pessoas aprisionadas, dados do Levantamento Nacional de Informações Penitenciárias mostram que, nos últimos anos, houve um aumento significativo do número de detentos no Brasil. O país possui a terceira maior população carcerária do mundo. Em 2002, havia um total de 239.345 presos condenados e provisórios; em 2014, o número subiu para 622.202 aprisionados; e, em 2019, o número total era de 752.277 presos. Esses dados nos mostram que, entre 2014 e 2019, houve um aumento de mais de 130 mil pessoas encarceradas no país (Instituto de Pesquisa Econômica Aplicada [lpea] \& Fórum Brasileiro de Segurança Pública [FBSP], 2019).

Entretanto, um dado que chama atenção é que são ofertadas apenas 350 mil vagas nos presídios, isto é menos da metade necessária para abarcar esse quantitativo de presos (Secco \& Lima, 2018). A taxa de ocupação de $197,4 \%$ revela que tanto as pessoas privadas de liberdade quanto os servidores e colaboradores que ocupam os espaços das prisões vivem em condições insalubres. No âmbito do Distrito Federal, segundo o levantamento do Ipea e FBSP (2019), a população carcerária é de 17.040 presos, enquanto a capacidade do sistema, ou seja, o número de vagas é de 7.398. É possível observar que os fatores relacionados ao índice de criminalidade no Brasil podem estar associados à questão da desigualdade social e às problemáticas, como a falta de escolaridade e de oportunidades de trabalho que impulsionam diretamente as taxas de criminalidade (Fonseca \& Rodrigues, 2017; Rolim, 2018). Além disso, pesquisas realizadas associam o aumento da população carcerária muito mais em decorrência de uma alteração da
Lei $n^{\circ} 11.343$, de 23 de agosto de 2006, chamada Lei das Drogas, que vem impulsionar o aprisionamento feminino no país (Braga, 2017; Dutra 2018).

Neste cenário, já é possível observar a necessidade de uma atuação estatal, quer seja na esfera estadual ou federal, que proporcione um retorno adequado desses presos à sociedade. No entanto, essa atuação não pode caber apenas ao poder público, mas também a diversas organizações e instituições sociais que possuem deveres para com a sociedade na qual estão inseridas. Dando suporte a esse argumento, segundo Silva (2015), os esforços de diversos setores, como o Estado, a sociedade civil e empresas, são necessários para que se possa planejar e executar medidas que viabilizem a reinserção social do egresso do sistema prisional.

Segundo Lima (2017, p. 100):

existem modelos de Reação Social e Prevenção da Criminalidade, sendo um deles o Restaurador, fundado na Política de Justiça Restaurativa. Tal modelo de Prevenção é constante no macro modelo de Prevenção e Combate à criminalidade, dividindo em três momentos: 1) Prevenção Primária, 2) Prevenção Secundária e 3) Prevenção Terciária. A primeira delas consta como núcleo incrementador o real investimento

e efetivação em políticas públicas para colocar em vigor os direitos fundamentais, como educação, saúde, segurança pública, trabalho, dentre outros. O segundo deles tem como objeto a aparelhagem policial, atuando como modelo posterior ao crime, visando combatê-lo no momento da sua atividade. Por fim, o terceiro deles tem como objeto evitar a reincidência de indivíduos no mundo do crime, emprega-se o conceito de prevenção terciária, por fim, para nomear projetos delineados para grupos que já se envolveram com o crime.

Diante desse contexto, é importante analisar o papel da prevenção terciária na inclusão social de egressos do sistema prisional, no mundo do trabalho. De acordo com Dias e Oliveira (2014), o trabalho contribui para o processo de ressocialização desses indivíduos na medida em que os coloca em contato com a sociedade, possibilitando-os vender a sua força de trabalho em prol de uma vida mais digna. É possível ainda afirmar, segundo J. E. Santos (2019), que o emprego funciona como uma barreira ao comportamento ilegal, pois inibe situações de má conduta e proporciona acesso a incentivos econômicos e sociais não provenientes de crimes. Explicando a importância do trabalho, especificamente para os egressos 
prisionais, Rakis (2005) entende que o trabalho tem centralidade na vida dos indivíduos pois, sem a segurança de um emprego, grande parte dos egressos não consegue sustentar a si e à sua família, enquanto que o desemprego marca o indivíduo com a exclusão do processo social de produção de bens serviços e riquezas (Albornoz, 2008).

Considerando os aspectos até aqui discutidos, a presente pesquisa tem como objetivo analisar a literatura científica sobre a reinserção social de egressos do sistema prisional no mercado de trabalho, a fim de caracterizar as tendências nessas produções.

\section{Materiais e Métodos}

Esta pesquisa é uma revisão sistemática. De acordo com Ferreira (2002), nesse tipo de pesquisa o objetivo é conhecer o que tem sido produzido em âmbito acadêmico sobre um tema específico e discutir essa produção, considerando o tempo, o lugar e o contexto. A metodologia desse tipo de pesquisa possui caráter "inventariante e descritivo das produções acadêmicas e científicas sobre o tema" (Ferreira, 2002, p. 258). Segundo Zoltowski et al. (2014, p. 97), revisão sistemática é "uma estratégia de busca das produções científicas, uma análise crítica e uma síntese do que foi encontrado". Para a realização da presente revisão sistemática da literatura, a pergunta norteadora foi: Como a literatura científica nacional e internacional evidencia inserção no mercado de trabalho de egressos do sistema prisional?

\section{Estratégia de busca dos estudos}

Para identificar a produção científica sobre os egressos do sistema prisional, a base de dados escolhida foi o Portal de Periódicos da Coordenação de Aperfeiçoamento de Pessoal de Nível Superior (Capes, n.d.). O portal é uma biblioteca virtual que reúne e disponibiliza a instituições de ensino e pesquisa no Brasil a produção científica internacional. Ele conta com um acervo de mais de 45 mil títulos com texto completo, 130 bases referenciais, 12 bases dedicadas exclusivamente a patentes, além de livros, enciclopédias e obras de referência, normas técnicas, estatísticas e conteúdo audiovisual. Em relação à etapa da revisão bibliográfica, ela foi realizada no período de fevereiro a junho de 2019.
Os temas da área do projeto foram divididos em quatro eixos, a saber: vulnerabilidade social, sistema prisional, cooperativismo e reciclagem; desta forma, foram utilizados os termos "egresso" e "cooperativa" como descritores primários, e os termos "ex-presidiário", "patronato" e "reciclagem" como descritores secundários. Nas bases de dados, as buscas foram realizadas da seguinte maneira: (egresso) AND (patronato) OR (sistema prisional) OR (ex-presidiário); (cooperativismo) AND (reciclagem) OR (sistema prisional) OR (ex-presidiário), bem como seus respectivos termos em inglês.

Foram considerados elegíveis para esta revisão artigos originais que investigassem as trajetórias laborais de egressos do sistema prisional, artigos publicados em língua portuguesa, inglesa ou espanhola, estudos com abordagem quantitativa, qualitativa ou mista e com textos completos disponíveis na íntegra pelo meio on-line até o dia 15 de setembro de 2019. Foram excluídos livros, artigos de revisão, resumos de congresso, editoriais e cartas. O limite temporal para a busca dos estudos foi de 2009 a 2019.

A seleção dos estudos foi realizada por dois autores de forma independente (A e B), sendo os desacordos resolvidos por consenso. Após a busca, iniciou-se a seleção dos estudos por meio da análise dos títulos. Na segunda etapa, foram analisados os resumos e, posteriormente, foi realizada a análise do texto na íntegra dos artigos selecionados nas etapas anteriores. Para a extração dos dados, foi construído um formulário especifico, onde foram registradas informações concernentes aos autores, ano de publicação, local/ país, desenho do estudo, técnica de coleta dos dados, tipo de análise, número da amostra e principais resultados verificados.

\section{Resultado}

O levantamento resultou em 555 ocorrências, das quais 92 foram removidas por duplicidade. Assim, passou-se ao processo de seleção a partir do critério de afinidade temática com a pesquisa pela leitura dos resumos. Nesse processo, foram lidos o título e o resumo de 463 artigos e excluídos 319, por não estarem relacionados aos eixos temáticos definidos no projeto. $\mathrm{O}$ escopo da pesquisa bibliográfica ficou, assim, definido em 144 artigos. Realizou-se, também, 
a análise criteriosa e a leitura integral dos artigos. Deste modo, 10 artigos foram eleitos para formar a base da análise deste estudo. A partir da análise independente dos juízes, houve consenso quanto aos artigos selecionados, não havendo a necessidade de acionar um terceiro juiz. O detalhamento da seleção dos artigos pode ser observado na Figura 1.

Figura 1. Fluxograma de identificação e seleção das publicações.

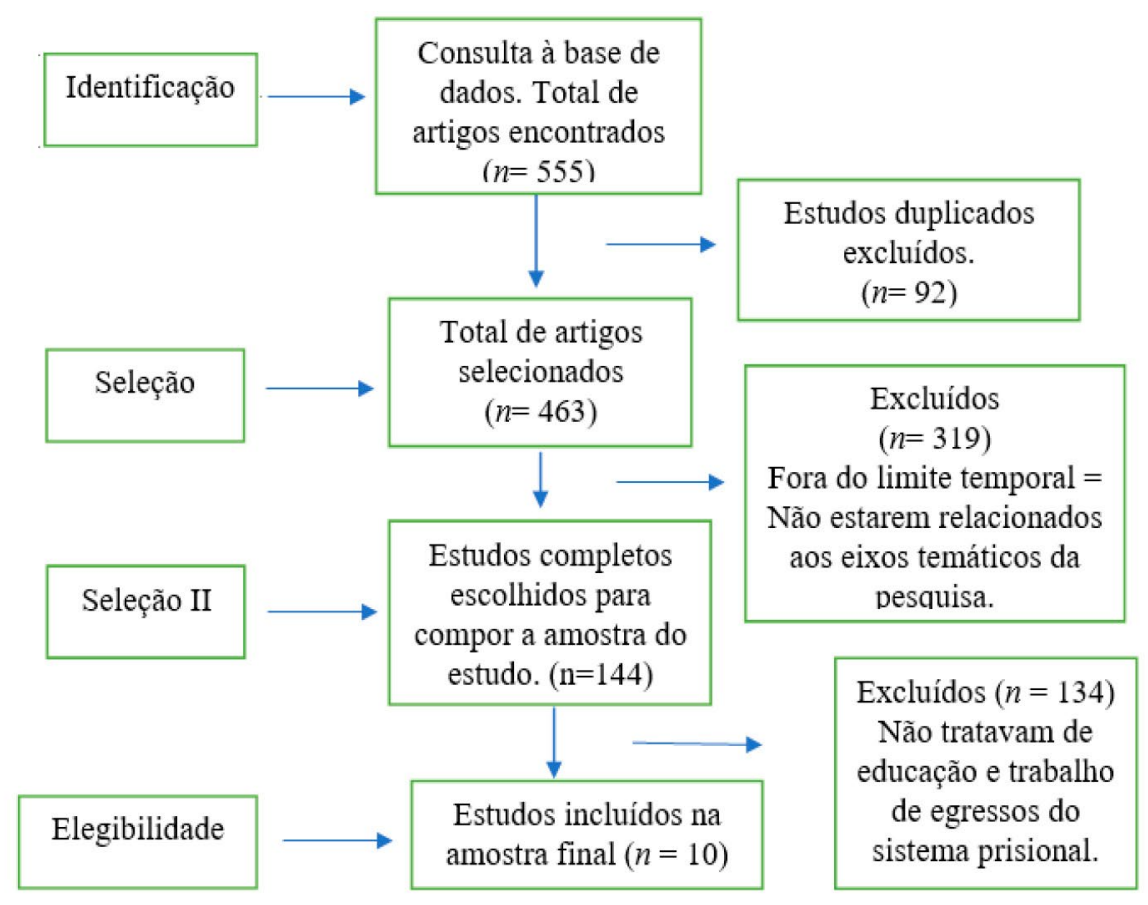

Todos os artigos analisados foram escritos em língua portuguesa, entre 2009 e 2019, no Brasil, e a maior parte dos estudos foram realizados nos estados de Minas Gerais e Rio grande do Sul.

Para a construção deste estudo, optou-se pela leitura na íntegra de todas as publicações analisadas. O conteúdo foi organizado e sumarizado em fichas de leitura individuais. As informações para cada artigo, no banco de dados, abrangeram o título do artigo, o autor, o ano de publicação, local de publicação, desenho da pesquisa, técnica de coleta de dados, método de análise, número de participantes, principais conclusões. As informações obtidas nos resultados dos 10 artigos incluídos foram categorizadas e discutidas segundo o tema, na seguinte ordem: prevenção terciária, ressocialização, preconceito, entidades acolhimento e redirecionamento da população egressa.

Quanto ao número de autores, observa-se que a maior parte dos estudos - 8 (80\%) textos - foi publicada por até dois autores. Na maior parte das pesquisas, 9 (90\%) artigos utilizaram o enfoque qualitativo, 1 (10\%) fez uso de ambas as abordagens. Para abordar o assunto, os autores utilizaram diferentes métodos de pesquisa ou análise de dados. Os principais resultados estão retratados na Tabela 1. 
Tabela 1. Estudos sobre a reinserção social de egressos do sistema prisional no mercado de trabalho publicados entre 2009 a 2019 (continua)

\begin{tabular}{|c|c|c|c|c|c|c|}
\hline $\begin{array}{c}\text { Autor/ } \\
\text { Ano }\end{array}$ & Local & Desenho & $\begin{array}{c}\text { Técnica de Coleta } \\
\text { de dados }\end{array}$ & Análise & $\begin{array}{l}\text { Sujeito/(n) de } \\
\text { participantes }\end{array}$ & $\begin{array}{l}\text { Principais } \\
\text { conclusões }\end{array}$ \\
\hline $\begin{array}{l}\text { Barbalho e } \\
\text { Barros } \\
(2014)\end{array}$ & $\begin{array}{l}\text { Brasil/ } \\
\text { MG }\end{array}$ & $\begin{array}{l}\text { Pesquisa } \\
\text { qualitativa }\end{array}$ & $\begin{array}{l}\text { Entrevistas } \\
\text { semiestruturadas }\end{array}$ & $\begin{array}{l}\text { Diretriz } \\
\text { teórico- } \\
\text { metodoló-gica } \\
\text { a Ergologia }\end{array}$ & $\begin{array}{l}\text { Egressos do } \\
\text { sistema } \\
\text { prisional do } \\
\text { sexo } \\
\text { masculino } \\
\text { adulto/ } \\
(n=15)\end{array}$ & $\begin{array}{l}\text { Vagas ofertadas por } \\
\text { meio do Projeto } \\
\text { Regresso é na } \\
\text { construção civil, na } \\
\text { função de servente } \\
\text { de pedreiro. }\end{array}$ \\
\hline $\begin{array}{l}\text { Faria e } \\
\text { Barros } \\
(2011)\end{array}$ & $\begin{array}{l}\text { Brasil/ } \\
\text { MG }\end{array}$ & $\begin{array}{l}\text { Pesquisa } \\
\text { qualitativa }\end{array}$ & $\begin{array}{l}\text { Entrevistas em } \\
\text { profundidade } \\
\text { História de Vida } \\
\text { Psicossociologia } \\
\text { Clínica }\end{array}$ & Análise clínica & $\begin{array}{l}\text { Homem } \\
(n=1)\end{array}$ & $\begin{array}{l}\text { Os envolvidos com } \\
\text { o tráfico, } \\
\text { consideram este } \\
\text { como trabalho. } \\
\text { Grande dificuldade } \\
\text { de se inserir no } \\
\text { mercado normal em } \\
\text { termos financeiros o } \\
\text { crime é mais rentável } \\
\text { que o trabalho } \\
\text { normal. }\end{array}$ \\
\hline $\begin{array}{l}\text { Fonseca e } \\
\text { Kamimura } \\
(2012)\end{array}$ & $\begin{array}{l}\text { Brasil/ } \\
\text { SP }\end{array}$ & $\begin{array}{l}\text { Quanti- } \\
\text { qualitativa }\end{array}$ & Estudo de caso & $\begin{array}{l}\text { Entrevista } \\
\text { semiestrutu- } \\
\text { rada, } \\
\text { observação } \\
\text { não } \\
\text { participante e } \\
\text { pesquisa } \\
\text { bibliográfica }\end{array}$ & $\begin{array}{l}\text { Homem } \\
(n=418)\end{array}$ & $\begin{array}{l}\text { Após a prisão houve } \\
\text { o agravante dos } \\
\text { antecedentes } \\
\text { criminais } \\
\text { dificultando o } \\
\text { acesso ao mercado } \\
\text { de trabalho. }\end{array}$ \\
\hline $\begin{array}{l}\text { Lauermann e } \\
\text { Guazina } \\
\text { (2013) }\end{array}$ & $\begin{array}{l}\text { e Brasil/ } \\
\text { RS }\end{array}$ & $\begin{array}{l}\text { Pesquisa } \\
\text { qualitativa }\end{array}$ & $\begin{array}{l}\text { Entrevistas } \\
\text { semiestruturadas } \\
\text { presencial }\end{array}$ & $\begin{array}{l}\text { Análise do } \\
\text { discurso }\end{array}$ & $\begin{array}{l}\text { Homens } \\
\text { Maiores de } 26 \\
\text { anos } \\
(n=4)\end{array}$ & $\begin{array}{l}\text { A instituição prisional, } \\
\text { dificulta a inserção } \\
\text { dos egressos no } \\
\text { mercado de trabalho } \\
\text { e na vida social. }\end{array}$ \\
\hline $\begin{array}{l}\text { Paula et al. } \\
(2016)\end{array}$ & $\begin{array}{l}\text { Brasil/ } \\
\text { PR }\end{array}$ & $\begin{array}{l}\text { Pesquisa } \\
\text { descritiva }\end{array}$ & $\begin{array}{l}\text { Relato de } \\
\text { experiência }\end{array}$ & Descrição & Ação & $\begin{array}{l}\text { A equipe se reúne } \\
\text { buscando identificar as } \\
\text { habilidades e aptidões } \\
\text { do assistido } \\
\text { verificando vagas de } \\
\text { trabalho disponiveis. }\end{array}$ \\
\hline $\begin{array}{l}\text { Ribeiro } \\
(2017)\end{array}$ & $\begin{array}{l}\text { Brasil/ } \\
\text { MG }\end{array}$ & $\begin{array}{l}\text { Pesquisa } \\
\text { qualitativa }\end{array}$ & $\begin{array}{l}\text { Coleta de } \\
\text { documental }\end{array}$ & $\begin{array}{l}\text { Análise de } \\
\text { conteúdo }\end{array}$ & $\begin{array}{l}\text { Documentos } \\
(n=4)\end{array}$ & $\begin{array}{l}\text { Para ex-detentas o } \\
\text { mercado de trabalho, é } \\
\text { difícil para as mulheres; } \\
\text { nem mesmo nas } \\
\text { próprias famílias elas } \\
\text { encontram apoio. }\end{array}$ \\
\hline $\begin{array}{l}\text { Rudnicki et } \\
\text { al. (2017) }\end{array}$ & $\begin{array}{l}\text { Brasil/ } \\
\text { RS }\end{array}$ & $\begin{array}{l}\text { Pesquisa } \\
\text { qualitativa }\end{array}$ & $\begin{array}{l}\text { Revisão } \\
\text { bibliográfica/ } \\
\text { Entrevista }\end{array}$ & $\begin{array}{l}\text { Analise na } \\
\text { perspectiva } \\
\text { de curso de } \\
\text { vida }\end{array}$ & $\begin{array}{l}\text { Mulheres } \\
\text { /Homens } \\
(\mathrm{n}=27)\end{array}$ & $\begin{array}{l}\text { O acolhimento em uma } \\
\text { comunidade serve para } \\
\text { modelar a perspectiva } \\
\text { de uma vida normal; } \\
\text { permite que as normas } \\
\text { sejam compartilhadas a } \\
\text { integração prevenindo } \\
\text { desvios secundários. } \\
\text { As oportunidades de } \\
\text { emprego restritas para } \\
\text { mulheres ou, até } \\
\text { mesmo, não existirão, } \\
\text { mesmo em delito de } \\
\text { pouca significância. }\end{array}$ \\
\hline
\end{tabular}


Tabela 1. Estudos sobre a reinserção social de egressos do sistema prisional no mercado de trabalho publicados entre 2009 a 2019 (conclusão)

\begin{tabular}{|c|c|c|c|c|c|c|}
\hline $\begin{array}{c}\text { Autor/ } \\
\text { Ano }\end{array}$ & Local & Desenho & $\begin{array}{c}\text { Técnica de Coleta } \\
\text { de dados }\end{array}$ & Análise & $\begin{array}{l}\text { Sujeito } /\left(n^{\circ}\right) \text { de } \\
\text { participantes }\end{array}$ & $\begin{array}{l}\text { Principais } \\
\text { conclusões }\end{array}$ \\
\hline $\begin{array}{l}\text { J. B. Santos } \\
\text { et al. } \\
\text { (2013). }\end{array}$ & $\begin{array}{l}\text { Brasil/ } \\
\text { CE }\end{array}$ & $\begin{array}{l}\text { Pesquisa } \\
\text { qualitativa }\end{array}$ & $\begin{array}{l}\text { estudo de } \\
\text { inspiração } \\
\text { etnográfica como } \\
\text { ferramentas a } \\
\text { observação direta } \\
\text { e entrevistas } \\
\text { semiestruturadas. }\end{array}$ & $\begin{array}{l}\text { Analise do } \\
\text { discurso }\end{array}$ & $\begin{array}{l}\text { Egressos do } \\
\text { sistema } \\
\text { prisional/ } \\
\text { Homens }\end{array}$ & $\begin{array}{l}\text { Ex-detentos catadores } \\
\text { de lixo condições } \\
\text { precárias de trabalho e } \\
\text { conflitos com o } \\
\text { "depósito" (dono do } \\
\text { depósito). }\end{array}$ \\
\hline $\begin{array}{l}\text { Souza e } \\
\text { Silveira } \\
(2017)\end{array}$ & $\begin{array}{l}\text { Brasil/ } \\
\text { MG }\end{array}$ & $\begin{array}{l}\text { Pesquisa } \\
\text { qualitativa }\end{array}$ & $\begin{array}{l}\text { Entrevistas } \\
\text { semiestruturadas } \\
\text { presencial }\end{array}$ & $\begin{array}{l}\text { Estatística } \\
\text { descritiva/ } \\
\text { Percepção } \\
\text { do egresso }\end{array}$ & $\begin{array}{l}\text { Egressos do } \\
\text { sistema } \\
\text { prisional } \\
(n=1.112)\end{array}$ & $\begin{array}{l}\text { Egressos do sistema } \\
\text { prisional oferece pouca } \\
\text { oportunidade de } \\
\text { trabalho. Devido ao } \\
\text { baixo nível de } \\
\text { escolaridade e } \\
\text { habilitação profissional } \\
\text { além do estigma. }\end{array}$ \\
\hline
\end{tabular}

As produções analisadas apresentaram variadas escolhas metodológicas: entrevista semiestruturada, história de vida, etnografia, estudo de caso, relato de experiência, revisão bibliográfica, documental e outras. A maioria das produções $(9,4 \%)$ utilizou técnica de entrevistas para produção e coleta das informações, sendo presente tanto o uso exclusivo de entrevistas quanto o uso associado a outra técnica. O método etnográfico e a pesquisa documental foram citados cada um em $0,64 \%$ dos estudos.

\section{Discussão}

Os resultados dos estudos analisados tiveram objetivos distintos, tendo em comum a investigação de diferentes tipos de inserção de ex-detentos no mercado de trabalho, e apontam para um contingente de egressos do sistema prisional desempregados, portanto, as tendências dessas produções são caracterizadas pela restrição de encontrar trabalho. Para J. B. Santos et al. (2013), em seu estudo sobre os catadores de lixo egressos do sistema prisional em Fortaleza, foi possível constatar precariedade do trabalho anterior ao trabalho da catação, atrelados a condições de pobreza, pouca escolaridade e experiência e quase nenhuma qualificação profissional, fatores inibitórios da possibilidade de prevenção terciária. É na prevenção terciária que se encontram os projetos delineados para grupos que já se envolveram com o crime. No Brasil, pouco se investe em prevenção do crime e da violência, portanto, pode-se afirmar que a área mais negligenciada é exatamente a da prevenção terciária (Rolim et al., 2017).

Com o objetivo de diminuir esse impacto, por meio de um decreto presidencial (Decreto $n^{\circ} 9.450,2018$ ), foi instituída a Política Nacional de Trabalho no âmbito do Sistema Prisional (PNAT). O objetivo da PNAT é a ampliação e a qualificação da oferta de vagas de trabalho ao empreendedorismo e à formação profissional dos presos e egressos. Também regula o art. 40, $\$ 5^{\circ}$, da Lei $n^{\circ} 8.666 / 1993$. A ideia é a inserção das pessoas presas e egressas do sistema prisional no mundo do trabalho e na geração de renda.

A legislação do país prevê assistências ofertadas pelo Estado, relacionadas ao aspecto laboral, à pessoa presa e ao egresso do sistema prisional. Contudo, estar na lei não é garantia de acesso a esses direitos. "Quando ele deixa a unidade prisional, deixa-a como mais um desempregado em busca de inserção no mercado de trabalho." (Fonseca \& Kamimura, 2012, p. 155). Ademais, deverá concorrerá a vagas de trabalho com pessoas que não portam o estigma da criminalidade e irá se deparar com o descrédito dos empregadores frente a sua condição. Isso ocorre porque, na opinião da sociedade, a possibilidade de que um criminoso venha a cometer novos crimes é presumida, uma vez que ele demonstrou ser uma pessoa "sem respeito pela lei". 
Outro ponto a ser considerado é que a privação da liberdade e a exclusão social prorrogam-se pós-cumprimento de pena, dessa vez imposta pela sociedade que, tendo como combustível o preconceito, cerra todas as oportunidades, sejam sociais ou laborais, impedindo a plena liberdade do egresso do sistema prisional. A sociedade exclui os egressos quando, ao se candidatarem para vagas no mercado de trabalho, têm suas "fichas" consultadas e, automaticamente, descartadas. Uma pesquisa realizada no Paraná encontrou que, para $70 \%$ dos egressos do sistema prisional, o preconceito é o principal motivo de não conseguirem trabalho (Wauters, 2003). Com uma ficha criminal que segue a vida do ex-infrator - estigma que ele carrega eternamente -, há dificuldade de acesso a trabalho, impossibilitando-o de exercer cargo público e taxando-o socialmente, o que o torna despreparado para uma ressocialização.

Portanto, a "ressocialização", entendida como "trazer alguém que não estava inserido em sociedade, reinseri-lo, transformar de novo em algo (ou alguém) que, em algum momento, pertenceu a um determinado grupo social" (Barra, 2012, p. 27), pode ser tomada como uma das maneiras de se desenvolver a dignidade desses indivíduos, na medida em que possibilita criar expectativas acerca de um futuro perdido que vislumbrava entre as paredes de uma penitenciária, "detento de um sistema arcaico que apenas pune e não o prepara para retornar a vida em sociedade, além de oferecer condições de sobrevivência degradante e desumana" (Brandão \& Farias, 2013, p. 6).

A prioridade dos egressos na vida pós-cárcere é retornar ao mercado de trabalho, considerando que muitas famílias dependem de suas rendas. O trabaIho é entendido como necessidade de sobrevivência pessoal e familiar, e não como retorno moral à sociedade.

No que se refere às expectativas de vida desses egressos após a saída do sistema prisional, predominam os sentimentos de repressão e intimidação perante a punição, além do medo da consequência de se envolverem com o crime. Entretanto, existem relatos de sentimentos de esperança e encorajamento para uma vida melhor com a saída da prisão. Um aspecto apontado como motivador nesse período é o apoio familiar. Para alguns, a prisão representa uma mudança, um ponto importante em suas vidas, principalmente no que se refere às expectativas em relação à família
(Barbalho \& Barros, 2014; Fonseca \& Kamimura, 2012; Lauermann \& Guazina, 2013; Rolim, 2018).

A inserção de egressos no mercado de trabalho é algo complexo e que requer a compreensão de uma série de fatores individuais, sociais e econômicos. As maiores dificuldades vivenciadas pelos egressos são: o ajustamento às regras do mundo do trabaIho (cumprimento de rotinas, horários, obediência à hierarquia, etc.), concentração de postos de trabaIho em atividades braçais, frustração das expectativas de trabalho e renda almejada e a dificuldade das empresas em fazer a gestão dessa força de trabalho (Pastore, 2011).

As oportunidades às atividades laborais, segundo Fonseca e Rodrigues (2017), podem promover a elevação da autoestima do egresso e sua dignidade como forma de reconhecimento de que ele não está mais envolvido com o crime, promovendo sua autossuficiência, favorecendo a sua capacitação e, consequentemente, desenvolvendo a sua independência na vida em sociedade (Fonseca \& Rodrigues, 2017; Souza \& Silveira, 2017).

Existem entidades que se dedicam a inserir novamente o egresso prisional na sociedade, e são conhecidas como redes de apoio institucionais importantes para a obtenção de emprego e na redução das taxas de reincidência. É o caso do Projeto Regresso, que atua na inserção laboral desses egressos na construção civil, objetivando o não retorno dos egressos a situações de risco que podem levar ao crime. Os achados mostram que, com processo criminal, o emprego mais acessível é na construção civil, especial na função de servente de pedreiro (Barbalho \& Barros, 2014; Pastore, 2011; Souza \& Silveira, 2017).

Na visão da sociedade e dos próprios egressos, o trabalho é a ferramenta mais importante e a mais escassa. Programas que atuem na inserção laboral de egressos do sistema penitenciário devem visar ao não retorno desses indivíduos a situações que podem levar à criminalidade, permitir a vivência em universos diferentes dos prisionais e oferecer expectativas de vida para esses sujeitos. Assim, é indispensável que redes de apoio institucionais atuem em uma lógica que não objetive somente a contratação do sujeito, mas também os efeitos positivos do trabalho em outros âmbitos da vida do egresso, como nas relações familiares e comunitárias (Souza \& Silveira, 2017). 
Essas instituições atuam no sentido de colaborar na reinserção de egressos no mercado de trabalho, como trabalho direto com infratores, cooperativas de trabalho, entidades de formação e recolocação, projetos de empregabilidade, incubadoras de empreendedores, métodos sociorreligiosos, trabalho interdisciplinar, conselhos comunitários, entidades governamentais de ação direta, entidades governamentais de articulação (Ribeiro, 2017).

A inclusão social, a partir do trabalho honesto, constitui a melhor maneira de atender às necessidades sociais desses sujeitos. O exercício do direito ao trabaIho proporciona dignidade para os egressos na vida extramuros e oferece oportunidades para a autorrealização e o avanço na escala social. As expectativas desses indivíduos em relação ao trabalho limitam-se à aceitação do primeiro serviço que aparece, ainda que em profissões inferiores em relação às que exerciam anteriormente à passagem pelo sistema. Isso é ainda reforçado pelas dificuldades enfrentadas em relação aos antecedentes criminais e à baixa escolaridade daqueles que saem, e pela falta de profissionalização.

Essa prioridade relaciona-se à sobrevivência e não é determinada por escolhas próprias. Pesquisas acerca da realidade de acesso desses egressos do sistema penitenciário à educação e trabalho enquanto direitos sociais revelam a sua vontade em ascender profissionalmente dentro das empresas em que trabalham, mas não apontam planos concretos junto à empresa e nem fora dela (Fonseca \& Kamimura, 2012; Souza \& Silveira, 2017).

Por conta do preconceito disseminado, a corrente criminógena se robustece e a violência é retroalimentada. Ou seja, a instituição prisional, funcionando como um mecanismo de marginalização e reprodução da delinquência, dificulta a inserção dos egressos no mercado de trabalho e na vida social em geral. Com o estigma de criminosos, aumentam-se as chances desses sujeitos tornarem-se alvo de uma vigilância discriminatória, configurando um aprisionamento que não acaba mesmo com o cumprimento da pena (Lauermann \& Guazina, 2013; Ribeiro, 2017; Rolim, 2018; Rudnicki et al., 2017).

\section{Considerações Finais}

Diante de tudo o que foi pesquisado, foi possível responder à pergunta de pesquisa: Como a literatura científica nacional e internacional evidencia inserção no mercado de trabalho de egressos do sistema prisional? Considerando que as publicações encontradas foram sobre a realidade brasileira, entende-se que os ex-detentos brasileiros terão maiores dificuldades para um reingresso digno em termos de oportunidades de emprego e igualdade na sociedade. Entretanto, foi possível elaborar pontos importantes na discussão proposta.

O sistema prisional do Brasil, como um dos principais tópicos desta pesquisa, mostrou a ineficiência no âmbito de ressocialização e evidencia a predominância de estudos com egressos do sexo masculino. Com relação à temática gênero, não foram encontrados estudos sobre a população de travesti ou transsexuais. Considera-se necessária a produção de conhecimentos com foco nas temáticas de gênero e trabalho.

Vale lembrar a importância de uma mudança social que quebre os preconceitos acerca dos ex-detentos, mas também é preciso que haja uma preparação educacional dessas pessoas, durante seu período de prisão, visando, mais do que uma formação técnica, a uma formação mais plena. Mas, apesar disso, se faz necessário o investimento em mais investigações que produzam conhecimentos e informações contextualizadas, coerentes e humanizadas, bem como indicadores para execução de uma política de direitos a essa população.

\section{Agradecimentos}

A presente pesquisa intitulada Egressos do Sistema Prisional: Histórias que importam foi realizada graças ao apoio e CNPQ, chamamento Público n²0/2013, processo n²5000.229370/2013-81.

\section{Contribuição das autoras}

Penso, M. A. participou da concepção, revisão e aprovação final do manuscrito. Silva, J. F. participou da coleta de dados e revisão do manuscrito. Silva, L. G. A. participou da coleta e análise de dados e redação do manuscrito. Oliveira, M. L. C. participou da análise dos dados e redação do manuscrito. 


\section{Conflitos de interesses}

Nenhum conflito financeiro, legal ou político envolvendo terceiros (governo, empresas e fundações privadas, etc.) foi declarado para nenhum aspecto do trabalho submetido (incluindo, mas não se limitando a subvenções e financiamentos, participação em conselho consultivo, desenho de estudo, preparação de manuscrito, análise estatística, etc.).

\section{Referências}

Albornoz, S. (2008). O que é trabalho. Coleção Primeiros Passos. Brasiliense.

Barbalho, L. A. B., \& Barros, V. A. (2014). Entre a cruz e a espada: a reintegração de egressos do sistema prisional a partir da política pública do governo de Minas Gerais. Psicologia em Revista, 20(3), 549-565. http://pepsic. bvsalud.org/scielo.php?script=sci abstract\&pid=S1677$11682014000300009 \&$ Ing=pt\&nrm=iso

Barra, B. T. A. (2012). O conceito de ressocialização e sua relação com a pedagogia do oprimido [Monografia de especialização, Universidade Federal do Ceará, Fortaleza]. http://www.repositorio.ufc.br/bitstream/ riufc/29177/1/2012_tcc_tbabarra.pdf

Braga, G. M. S. (2017). O impacto da nova lei de drogas no sistema carcerário brasileiro [Trabalho de Conclusão de Curso, Pontifícia Universidade Católica do Rio Grande do Sul]. https://www.pucrs.br/direito/wp-content/uploads/ sites/11/2018/03/gabriela_braga_20172.pdf

Brandão, J. M. F., Farias, A. C. A. (2013, 3-5 de novembro). Inclusão social de ex-detentos no mercado de trabalho: reflexões acerca do projeto esperança viva. Anais do IV Encontro de Gestão de Pessoas e Relações de Trabalho. ANPAD. http:// www.anpad.org.br/admin/pdf/EnGPR212.pdf

Coordenação de Aperfeiçoamento de Pessoal de Nível Superior (n.d.). Portal de Periódicos da Capes. Acervo. http:// www.periodicos.capes.gov.br/index.php?option=com pcollection\&ltemid $=104$

Decreto n. 9.450, de 24 de julho de 2018. (2018). Institui a Política Nacional de Trabalho no âmbito do Sistema Prisional, voltada à ampliação e qualificação da oferta de vagas de trabalho, ao empreendedorismo e à formação profissional das pessoas presas e egressas do sistema prisional, e regulamenta o $\S 5^{\circ}$ do art. 40 da Lei $n^{\circ} 8.666$, de 21 de junho de 1993, que regulamenta o disposto no inciso XXI do caput do art. 37 da Constituição e institui normas para licitações e contratos da administração pública firmados pelo Poder Executivo federal. http://www.planalto.gov.br/ ccivil 03/ Ato2015-2018/2018/Decreto/D9450.htm
Dias, S., \& Oliveira, L. J. (2014). A Reinserção Social Através do Trabalho: Responsabilidade Empresarial no Resgate da Dignidade da Pessoa Humana. Revista Jurídica CesumarMestrado, 14(1), 143-169. https://periodicos.unicesumar. edu.br/index.php/revjuridica/article/view/3248

Dutra, V. R. L. (2018). Guerra às drogas no Brasil: os impactos dessa política sobre o encarceramento feminino [Monografia, Pontifícia Universidade Católica do Rio Grande do Sul]. https://www.pucrs.br/direito/wp-content/uploads/ sites/11/2018/09/vera_dutra.pdf

Faria, A. A. C., \& Barros, V. A. (2011). Tráfico de drogas: uma opção entre escolhas escassas. Psicologia \& Sociedade, 23(3), 536544. https://doi.org/10.1590/S0102-71822011000300011

Ferreira, N. S. A. (2002). As pesquisas denominadas "estado da arte". Educação \& Sociedade, 9(1), 257-272. https://doi. org/10.1590/S0101-73302002000300013

Fonseca, C. E. P., \& Rodrigues, J. M. (2017). Contextos de ressocialização do privado de liberdade no atual sistema prisional brasileiro. Revista Multitexto, 5(1), 35-44. http:// www.ead.unimontes.br/multitexto/index.php/rmcead/ article/view/189

Fonseca, K. H. C., \& Kamimura, Q. P. (2012). Egressos do sistema penitenciário: um estudo sobre o acesso aos direitos sociais, com ênfase em educação e trabalho. Revista Debates, 6(3), 145-163. https://doi.org/10.22456/1982$\underline{5269.29657}$

Instituto de Pesquisa Econômica Aplicada \& Fórum Brasileiro de Segurança Pública. (2019). Atlas da violência 2019. https:// www.ipea.gov.br/portal/images/stories/PDFs/relatorio institucional/190605_atlas_da_violencia_2019.pdf

Lauermann, J. D., \& Guazina, F. M. N. (2013). Para além dos muros institucionais: problematizando os discursos dos egressos do sistema prisional. Barbaroi, (38), 178-197. http://pepsic. bvsalud.org/pdf/barbaroi/n38/n38a10.pdf

Lima Jr, J. C. N. (2017). Manual de Criminologia. Editora Juspodivum.

Pastore, J. (2011). Trabalho para Ex-Infratores. Saraiva.

Paula, S. C. M. N. G., Paula, B. B., Sessak, L., \& Cassaro, S. E. (2016). Patronato Municipal de Apucarana: Atenção ao egresso do sistema penitenciário e à sua família. Revista Caminho Aberto, 1(3), 147-151. http://dx.doi.org/10.35700/ca.2015. ano2n3.p147-151.1621

Rakis, J. (2005). Improving the Employment Rates of Ex-Prisoners Under Parole [Melhoria das taxas de emprego de ex-presidiários em liberdade condicional]. Federal Probation, 69(1), 7-12. https://www.researchgate.net/ publication/285862299_Improving the_employment rates of ex-prisoners under parole 
Ribeiro, F. (2017). A reinserção social da ex-presidiária no mercado de trabalho. Revista de Ciências do Estado, 2(1), 357-379. https://periodicos.ufmg.br/index.php/revice/ article/view/5030

Rolim, M. (2018). Desistência do crime. Sociedade e Estado, 33(3), 829-847. https://dx.doi.org/10.1590/s0102-6992201833030008

Rolim, M., Braga, C., \& Wilkelman, F. (2017). POD RS Socioeducativo e a potência da prevenção terciária. Revista Brasileira de Segurança Pública, 11(1):148-162. https:// revista.forumseguranca.org.br/index.php/rbsp/article/ view/785/255

Rudnicki, D., Schäfer, G., \& Silva, J. C. (2017). As máculas da prisão: estigma e discriminação das agentes penitenciárias. Revista Direito GV, 13(2), 608-627. https://dx.doi. org/10.1590/2317-6172201724

Santos, J. B. F., Maciel, R. H. M. O., \& Matos, T. G. R. (2013). Reconquista da identidade de trabalhador por exdetentos catadores de lixo. Caderno CRH, 26(68), 377-390. https://doi.org/10.1590/S0103-49792013000200011

Santos, J. E., Barbosa, M. A. C., Cassundé, F. R., \& Lima, J. R. T. (2019). Egressos do sistema prisional e gestão de pessoas em organizações alagoanas. Revista de Administração FACES Journal, 18(2), 65-83. http://revista.fumec.br/index. php/facesp/article/view/6138
Secco, M., \& Lima, E. P. (2018). Justiça restaurativa - problemas e perspectivas. Revista Direito e Práxis, 9(1), 443-460. https:// doi.org/10.1590/2179-8966/2018/32715

Silva Jr, E. C. (2015). O caráter ressocializador da pena: as políticas públicas prisionais no processo de ressocialização do reeducando. Revista Três Pontos - Dossiê Estado, Governo e Políticas Públicas, 12(2), 59-67. https://periodicos.ufmg.br/ index.php/revistatrespontos/article/view/3343

Souza, R. L., \& Silveira, A. M. (2017). Egressos do sistema prisional no mercado formal de trabalho: oportunidade real de inclusão social? Revista de Políticas Públicas, 21(2), 761-779. http://dx.doi.org/10.18764/2178-2865.v21n2p761-780

Wauters, E. (2003). A reinserção social pelo trabalho [Monografia de especialização, Universidade Federal do Paraná, Curitiba]. http://www.depen.pr.gov.br/arquivos/File/monografia ednaw.pdf

Zoltowski, A. P. C., Costa, A. B., Teixeira, M. A. P., \& Koller, S. H. (2014). Qualidade metodológica das revisões sistemáticas em periódicos de psicologia brasileiros. Psicologia: Teoria e Pesquisa, 30(1), 97-104. https://doi.org/10.1590/50102$\underline{37722014000100012}$ 